\title{
An Overview of Normally-Off GaN-Based High Electron Mobility Transistors
}

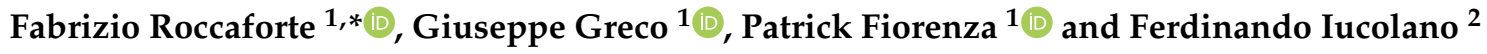 \\ 1 Consiglio Nazionale delle Ricerche-Istituto per la Microelettronica e Microsistemi (CNR-IMM) Strada VIII, \\ n. 5-Zona Industriale, Catania 95121, Italy; giuseppe.greco@imm.cnr.it (G.G.); \\ patrick.fiorenza@imm.cnr.it (P.F.) \\ 2 STMicroelectronics, Stradale Primosole 50, Catania 95121, Italy; ferdinando.iucolano@st.com \\ * Correspondence: fabrizio.roccaforte@imm.cnr.it
}

Received: 16 April 2019; Accepted: 14 May 2019; Published: 15 May 2019

\begin{abstract}
Today, the introduction of wide band gap (WBG) semiconductors in power electronics has become mandatory to improve the energy efficiency of devices and modules and to reduce the overall electric power consumption in the world. Due to its excellent properties, gallium nitride $(\mathrm{GaN})$ and related alloys (e.g., $\mathrm{Al}_{x} \mathrm{Ga}_{1-\mathrm{x}} \mathrm{N}$ ) are promising semiconductors for the next generation of high-power and high-frequency devices. However, there are still several technological concerns hindering the complete exploitation of these materials. As an example, high electron mobility transistors (HEMTs) based on $\mathrm{AlGaN} / \mathrm{GaN}$ heterostructures are inherently normally-on devices. However, normally-off operation is often desired in many power electronics applications. This review paper will give a brief overview on some scientific and technological aspects related to the current normally-off GaN HEMTs technology. A special focus will be put on the $\mathrm{p}-\mathrm{GaN}$ gate and on the recessed gate hybrid metal insulator semiconductor high electron mobility transistor (MISHEMT), discussing the role of the metal on the p-GaN gate and of the insulator in the recessed MISHEMT region. Finally, the advantages and disadvantages in the processing and performances of the most common technological solutions for normally-off $\mathrm{GaN}$ transistors will be summarized.
\end{abstract}

Keywords: gallium nitride; normally-off HEMT; power electronics

\section{Introduction}

Nowadays, one of the most important societal challenges is represented by the steady increase of the energy consumption in the world. In fact, the energy consumption is expected to increase by about $40 \%$ worldwide in the next 20 years [1], when the electricity will cover the largest fraction (up to 60\%) of the used energy. In this context, power electronics is the technology devoted to the control and management of electric power. In fact, power electronics systems are used to provide the optimal characteristics of electric power (i.e., current, voltage, frequency, etc.) for any targeted application.

For more than five decades, silicon (Si) has been the dominant semiconductor for power electronics devices. However, today the continuous demand for higher current, voltage and power density capability, as well as the need of a better energy efficiency to reduce the global energy consumption, are the driving forces to introduce new semiconductor technologies in power electronics and to overcome the inherent limitations of Si-based devices.

Wide band gap (WBG) semiconductors, like silicon carbide (4H-SiC) and gallium nitride (GaN), are considered the best materials for the future energy efficient power electronics [2]. However, while $4 \mathrm{H}-\mathrm{SiC}[3]$ is mature in terms of crystalline quality and available device performances, gallium nitride $(\mathrm{GaN})$ is still affected by several materials and technology concerns, limiting its full exploitation in power electronics applications [4]. 
This review paper will give a brief overview on some scientific and technological issues associated with the fabrication and performances of normally-off GaN-based high electron mobility transistors (HEMTs). In particular, the emphasis will be put on the $\mathrm{p}-\mathrm{GaN}$ gate and on the recessed gate hybrid metal insulator semiconductor high electron mobility transistor (MISHEMT) approaches, which are the most widely adopted technologies at either R\&D or commercial level.

\section{Gallium Nitride: Properties, Power Electronics Applications and Potential Market}

Gallium nitride $(\mathrm{GaN})$ is a wide band gap semiconductor whose stable crystalline structure is the hexagonal wurtzite. Table 1 reports the relevant physical and electronic properties of GaN, compared with those of silicon $(\mathrm{Si})$ and silicon carbide (4H-SiC). As can be seen, the wide band gap $(3.4 \mathrm{eV})$ results in an intrinsic carrier concentration $n_{i}$ that is several orders of magnitude lower than in Si. Consequently, GaN devices should have a lower leakage current and give the possibility to operate at higher temperatures. Other key aspects are the high critical electric field and the maximum reachable breakdown of the material, making $\mathrm{GaN}$ a promising semiconductor for high voltage devices. In particular, the possibility to obtain a targeted breakdown voltage $\left(V_{B}\right)$ with thinner drift layers results in a significant reduction of the specific on-resistance $\left(R_{O N}\right)$ with respect to Si devices. In this way, devices that are more compact can be fabricated, minimizing both the static and dynamic losses. Finally, $\mathrm{GaN}$ devices are expected to have a high-frequency switching capability, due to the high saturation electron velocity of the material. High frequency operation is possible also due to the presence of the two-dimensional electron gas (2DEG) in AlGaN/GaN heterostructures [5], whose mobility values typically exceed $1000 \mathrm{~cm}^{2} \cdot \mathrm{V}^{-1} \cdot \mathrm{s}^{-1}$. Table 1 reports also some figures of merit (FOM) used to quantify the performance of high power and high frequency devices, normalized with respect to silicon: Johnson's (JFOM), Baliga FOM (BFOM) and Baliga high frequency FOM (BHFOM) [6]. They quantify the maximum capability to energize carriers by electric field (JFOM), the minimum conduction losses during DC operation (BFOM), and the minimum conduction losses during high-frequency operation (BHFOM) [6]. The high values of the FOM clearly indicate the potential advantages offered from GaN devices with respect to the corresponding Si devices in high power and high frequency applications.

Table 1. Relevant physical and electronic properties of gallium nitride (GaN) compared with silicon (Si) and silicon carbide (4H-SiC). The figures of merit (FOM) for power and high frequency electronics, normalized with respect to $\mathrm{Si}$, are also reported. The table was compiled taking the data from Studies $[7,8]$ and the references therein.

\begin{tabular}{cccc}
\hline Property & Si & 4H-SiC & GaN \\
\hline Bandgap $(\mathrm{eV})$ & 1.12 & 3.2 & 3.4 \\
Critical field $\mathrm{E}_{\mathrm{cr}}(\mathrm{MV} / \mathrm{cm})$ & 0.25 & 3 & 4 \\
Dielectric constant $\varepsilon$ & 11.8 & 9.7 & 9.5 \\
Saturation velocity $\mathrm{v}_{\mathrm{s}}\left(10^{7} \mathrm{~cm} / \mathrm{s}\right)$ & 1 & 2 & 3 \\
Electron mobility $\mu\left(\mathrm{cm}^{2} / \mathrm{Vs}\right)$ & 1350 & 800 & $1300^{*}\left({ }^{2} \mathrm{DEG}\right)$ \\
Intrinsic carrier concentration $\mathrm{n}_{\mathrm{i}}\left(\mathrm{cm}^{-3}\right)$ at $300 \mathrm{~K}$ & $10^{10}$ & $10^{-7}$ & $10^{-10}$ \\
Thermal conductivity $\mathrm{k}(\mathrm{W} / \mathrm{cmK})$ & 1.5 & 4.9 & 1.3 \\
Figure of merit $(\mathrm{FOM})$ & - & - & - \\
JFOM $\left(\mathrm{v}_{\mathrm{s}} \mathrm{E}_{\mathrm{cr}}\right)^{2} /\left(\mathrm{v}_{\mathrm{s}} \mathrm{E}_{\mathrm{cr}}\right)^{2} \mathrm{Si}$ & 1 & 576 & 2304 \\
BFOM $\left(\varepsilon \mu \mathrm{E}_{\mathrm{cr}}{ }^{3}\right) /\left(\varepsilon \mu \mathrm{E}_{\mathrm{cr}}{ }^{3}\right) \mathrm{Si}$ & 1 & 842 & 3175 \\
BHFOM $\left(\mu \mathrm{E}_{\mathrm{cr}}{ }^{2}\right) /\left(\mu \mathrm{E}_{\mathrm{cr}}{ }^{2}\right) \mathrm{Si}$ & 1 & 85 & 246 \\
\hline
\end{tabular}

High electron mobility transistors (HEMTs) are lateral devices whose working principle is based on the presence of the 2DEG [9]. In the presence of the 2DEG acting as conduction channel, these devices are naturally normally-on, i.e., a current will flow between the source and drain electrodes even at zero bias to the gate $\left(\mathrm{V}_{\mathrm{g}}=0\right)$. Hence, the current is modulated by the application of a negative bias to a Schottky gate electrode. 
GaN-based HEMTs can be employed as switching devices in a large variety of high power applications. However, as will be specified in Section 3, normally-off transistors are preferred to guarantee a safe operation in power electronics systems.

Figure 1 schematically illustrates the potential applications of $\mathrm{GaN}$ devices in power electronics in the low-, medium- and high-voltage range. For comparison, the typical range of application of the other wide band gap semiconductor $\mathrm{SiC}$ is also indicated.

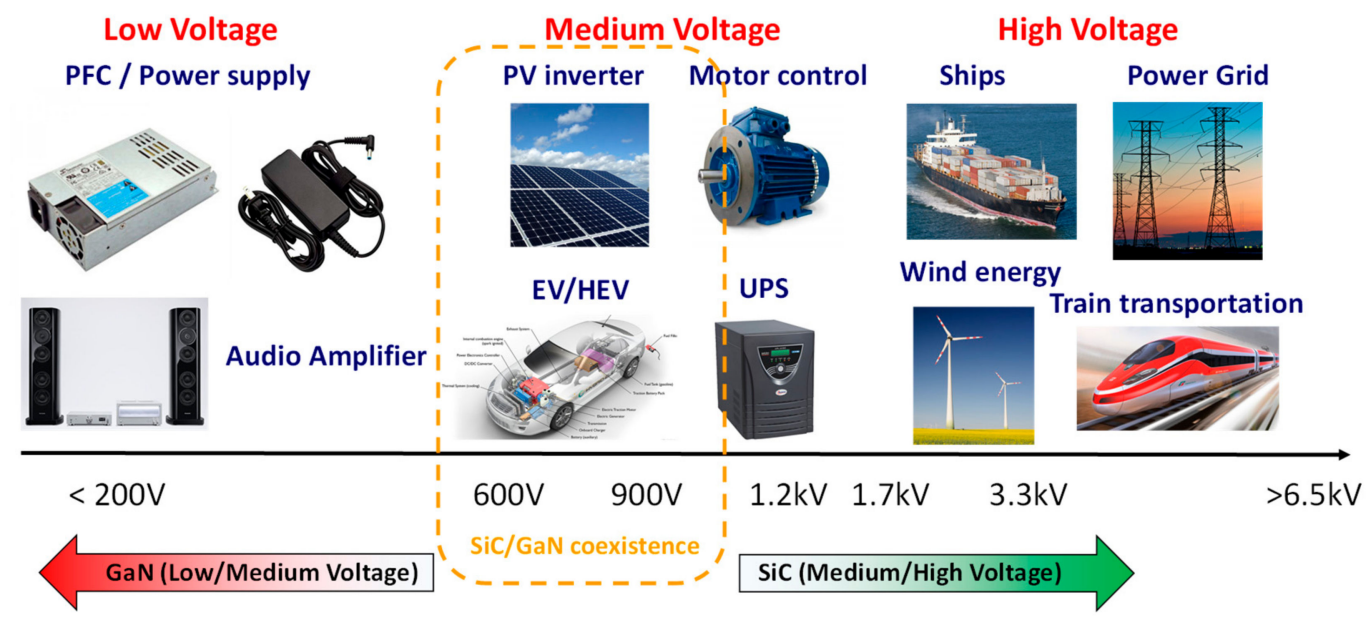

Figure 1. Possible applications of GaN power devices as a function of the voltage. The range of application of silicon carbide $(\mathrm{SiC})$ devices is also shown for comparison.

As recently reported by several market analysts, $\mathrm{GaN}$ is better suited for the low-medium voltage range (200-600 V), which includes a large portion of the consumer electronic market (e.g., computer power supplies, audio amplifiers, etc.). Indeed, in this voltage range, the material is indicated as the best candidate to replace the existing Si devices. Clearly, the $600-900 \mathrm{~V}$ voltage range is strategic, as it covers the converters for electric (EV) and hybrid electric vehicles (HEV), as well as inverters for renewable energy (e.g., photovoltaic). In this voltage range, $\mathrm{GaN}$ devices are expected to be in competition or to coexist with $\mathrm{SiC}$ ones. Finally, for the high voltage applications $(>1.2 \mathrm{kV})$, e.g., industrial applications, trains/ships transportation, electric energy distribution grids, etc.), $4 \mathrm{H}-\mathrm{SiC}$ remains at the moment the preferable choice, owing to a better material quality and device reliability. The future applications of GaN for high-voltage devices will strongly depend on the improvement of the material quality and the development of vertical devices based on bulk GaN [10].

In this wide scenario, $\mathrm{SiC}$ and $\mathrm{GaN}$ are expected to grow in share in the future of power electronics, as each material will enter in different applications, penetrating the market with a different speed. However, in power electronics, $\mathrm{GaN}$ is still a path away from $\mathrm{SiC}$. In fact, the material is less mature and, hence, it is currently less adopted. For that reason, the inclusion of $\mathrm{GaN}$ devices in power electronics products must be still justified by high benefits. In this context, the reliability is presently a major challenge for the application of $\mathrm{GaN}$ in power systems.

Despite all the current physical and technological issues related to $\mathrm{GaN}$, according to recent reports of market analysts [11], a bright future is envisaged for GaN power devices market, which is expected to exceed $\$ 450 \mathrm{M}$ in 2022. In this context, normally-off GaN-based HEMTs on large area $\mathrm{Si}$ substrates will play the dominant role, as the diffusion of vertical GaN power devices in the medium term will be still limited by the prohibitive cost of high quality large area bulk substrates.

\section{Normally-Off GaN HEMT Technology}

As introduced in Section 2, the normally-on GaN HEMT operation (i.e., the achievement of transistors with a negative threshold voltage, $\mathrm{V}_{\text {th }}<0$ ) lies in the nature of an AlGaN/GaN heterostructure, due to the presence of the 2DEG at the interface. However, normally-off switching 
devices are preferred in power electronics, as they offer more failsafe operation conditions and gate-driver circuitry simplicity [12-14]. For this reason, both the academic community and many industrial players (e.g., Panasonic, Infineon, GaNSystems, OnSemiconductors, STMicroelectronics) are currently addressing their research efforts on the development and commercialization of reliable normally-off technologies.

Under the physical point of view, to induce a positive shift the threshold voltage $\mathrm{V}_{\text {th }}$ and, hence, to obtain the desired normally-off HEMT behaviour, the region near the gate must be appropriately modified, e.g., by near-surface processing, or band engineering techniques.

The first solution proposed to achieve a normally-off HEMT was the "recessed gate" approach [15], which consists in the local reduction of the AlGaN barrier layer thickness under the gate. Below a certain AlGaN thickness, the Fermi level at the interface will lie below the AlGaN conduction band minimum, thus corresponding to the depletion of the 2DEG and to a positive threshold voltage $\mathrm{V}_{\text {th }}[15,16]$.

Another early approach has been the "fluorine gate" HEMT [17], consisting in the introduction of negatively charged fluorine ions below the gate electrode, either by plasma or ion-implantation processes. In fact, the introduced negative charge produces a positive shift of the $\mathrm{V}_{\text {th }}$ and a depletion of the 2DEG [18]. Furthermore, the negative fixed charges (i.e., the incorporated F-ions) will lead to an upward conduction band bending of the $\mathrm{AlGaN}$, causing an increase of the metal/AlGaN barrier height and, in principle, a reduction of the gate leakage current [12].

A further evolution of these approaches has been to combine the recessed gate layout with the introduction of fluorine below the gate [19]. In this case, a dielectric layer is also introduced below the metal gate in the recessed region to reduce the leakage current. In this way, the threshold voltage of the device can be better controlled by varying the dielectric layer thickness [19].

While these methods were the first to be proposed to fabricate normally-off GaN HEMTs, they present some limitations, essentially related to the control of reproducibility (at a nanometric level) of the plasma etch process, $V_{\text {th }}$ instabilities with increasing the operation temperature, etc. [20].

Today, the most popular solutions for normally-off GaN HEMTs are the "cascode" configuration, the "p-GaN gate" and the "recessed gate hybrid MISHEMT". These technologies will be described in more detail in the following sections, discussing their advantages and limitations.

\subsection{Cascode Configuration}

A normally-off GaN HEMT can be realized adopting the so called "cascode" configuration, which has been previously used both in $\mathrm{Si}$ and $4 \mathrm{H}-\mathrm{SiC}$ transistors to obtain a stable threshold voltage [21]. The "cascode" circuit, schematically shown in Figure 2, consists in the series connection of a low-voltage normally-off Si metal oxide semiconductor field effect transistor (MOSFET) with a high-voltage normally-on GaN HEMT. The two devices are connected in such a way that the output (drain-source) voltage of the MOSFET determines the input (gate-source) voltage of the HEMT. The devices share the same channel current in the on-state, while the blocking voltage is distributed between them in the off-state.

The "cascode" working principle can be summarized as follows. When the Si MOSFET is turned on with a positive gate bias above its threshold voltage, the normally-on GaN HEMT gate voltage is close to zero and the device is turned on. Hence, for any applied voltage to the drain terminal, the current will flow through the normally-on GaN HEMT and the Si MOSFET, as they are connected in series [21]. On the other hand, when the Si MOSFET is turned off by removing the gate voltage, an applied bias to the drain terminal will create a negative voltage between the gate and source electrodes of the GaN HEMT. Consequently, the 2DEG channel will be pinched off, and any further increase of the drain voltage will be supported by the GaN HEMT [21]. 


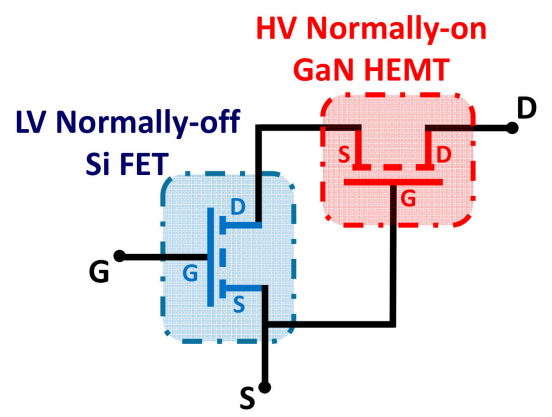

Figure 2. Normally-off GaN transistor obtained with the "cascode" configuration, combining a high-voltage (600 V) normally-on GaN high electron mobility transistors (HEMT) with a low-voltage (30 V) normally-off Si MOSFET.

With the "cascode" configuration, a positive and stable threshold voltage $\left(\mathrm{V}_{\text {th }}>0\right)$ is obtained like in a Si MOSFET. At the same time, the system maintains the benefits provided by $\mathrm{GaN}$ materials, i.e., a low series resistance of the 2DEG in the on-state and a high electric field strength in the off-state.

Since some years, normally-off GaN HEMTs using the "cascode" configuration rated at $600 \mathrm{~V}$ are commercially available [22]. However, while the "cascode" configuration has the advantage that can be driven by the conventional MOSFET drivers, this solution exhibits some drawbacks. As an example, the series connection of the two devices increases the package complexity, and introduces parasitic inductances that affect the switching performance of the cascode configuration. Moreover, the high temperature operation is limited by the presence of a Si device.

It is also important to point out that the "cascode" configuration work well when the GaN HEMT has a relatively high on-resistance with respect to the Si MOSFET (typically a $30 \mathrm{~V}$ device). In fact, since the on-resistance increases with increasing the rated breakdown voltage, the "cascode" approach is advantageous when the normally-on GaN HEMT is high-voltage and the Si MOSFET is low-voltage [23]. As an example, a $600 \mathrm{~V} \mathrm{GaN} \mathrm{HEMT} \mathrm{"cascode"} \mathrm{will} \mathrm{have} \mathrm{only} \mathrm{3 \%} \mathrm{added} \mathrm{on-resistance}$ due to the Si MOSFET. On the other hand, for lower targeted breakdown, the on-resistance of the GaN HEMT decreases and, hence, the contribution of the Si MOSFET becomes significant. Hence, the "cascode" approach is practically advantageous for applications above $200 \mathrm{~V}$ [23].

For the aforementioned reasons, today the power electronics community is continuously pushing towards the development of "real" normally-off GaN HEMT solutions, instead adopting the "cascode" configuration.

\section{2. $p-G a N$ Gate}

The structure of a normally-off HEMT with a p-GaN gate is schematically depicted in Figure 3a, together with an example of band structure of a $\mathrm{p}-\mathrm{GaN} / \mathrm{AlGaN} / \mathrm{GaN}$ system (Figure $3 \mathrm{~b}$ ). In particular, with respect to a standard normally-on HEMT with a Schottky gate, the presence of a p-GaN cap layer raises the AlGaN conduction band above the Fermi level. 
(a)

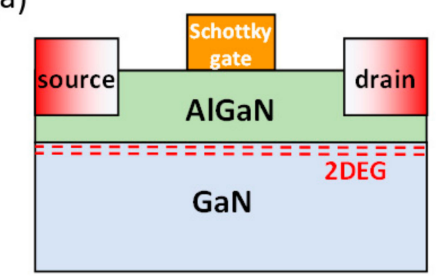

(b)

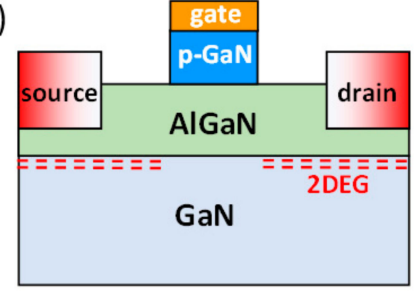

(c)

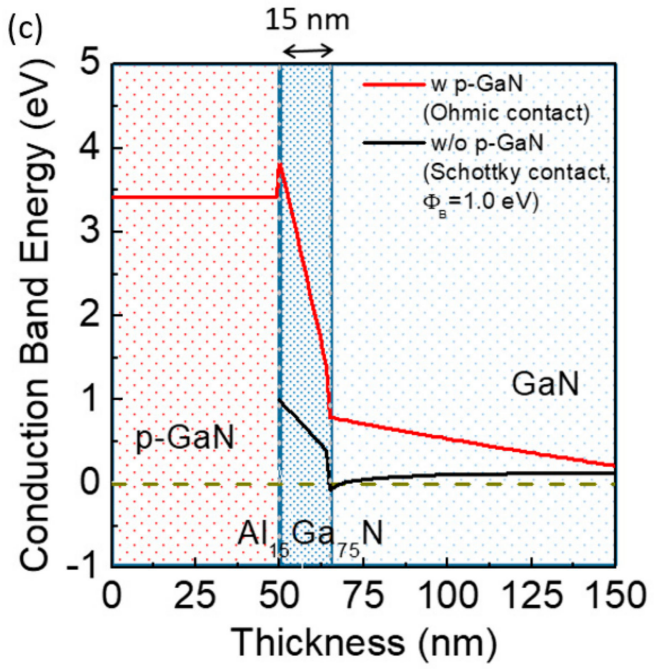

Figure 3. Schematic of a normally-on HEMT with a Schottky gate (a) and normally-off HEMT with a $\mathrm{p}-\mathrm{GaN}$ gate $(\mathbf{b})$; conduction band diagrams of a $\mathrm{p}-\mathrm{GaN} / \mathrm{AlGaN} / \mathrm{GaN}$ heterostructure simulated for a p-GaN layer $\left(3 \times 10^{19} \mathrm{~cm}^{-3}\right)$ of $50 \mathrm{~nm}$, an AlGaN thickness of $15 \mathrm{~nm}$ and $\mathrm{Al}$ concentration of $15 \%$ (c). The Fermi level (dashed line) lies below the conduction band, which indicates the depletion of the two-dimensional electron gas (2DEG) and a normally-off condition. For comparison, the band diagram of an $\mathrm{AlGaN} / \mathrm{GaN}$ heterostructure with a conventional Schottky gate is reported (normally-on).

The band structure reported in Figure $3 \mathrm{~b}$ was obtained by a commercial Poisson solver, for a p-GaN layer of $50 \mathrm{~nm}$ (with a doping level of $3 \times 10^{19} \mathrm{~cm}^{-3}$ ), an AlGaN thickness of $15 \mathrm{~nm}$ and Al concentration of $15 \%$. Under these conditions, the 2DEG can be depleted below the gate electrode and the normally-off operation is obtained, i.e., a positive gate bias will be needed to restore the electron charge in the channel.

Historically, the normally-off GaN HEMT with a p-AlGaN gate was first proposed by Uemoto et al. [24], and it exhibited a threshold voltage $\mathrm{V}_{\text {th }}=1.0 \mathrm{~V}$ and a breakdown $\mathrm{V}_{\mathrm{B}}=800 \mathrm{~V}$.

In order to achieve an efficient depletion of the $2 \mathrm{DEG}$ and $\mathrm{V}_{\mathrm{th}}>0$ the properties of the AlGaN/GaN heterostructure (i.e., thickness of the $\mathrm{AlGaN}$ barrier and Al-concentration) must be appropriately defined [25-28]. Typically, in a normally-off p-GaN/AlGaN/GaN heterostructure the AlGaN barrier layer thickness is in the range of $10-15 \mathrm{~nm}$, while the $\mathrm{Al}$ concentration is in the order of $15-20 \%$. Moreover, a high doping level of the $\mathrm{p}-\mathrm{GaN}$ layer $\left(>10^{18} \mathrm{~cm}^{-3}\right)$ is typically required for an efficient depletion of the region at the metal-gate/p-GaN interface [29]. In this sense, one of the key elements to improve the threshold voltage $\mathrm{V}_{\text {th }}$ for a fixed $\mathrm{Mg}$-concentration of the $\mathrm{p}-\mathrm{GaN}$ layer is to increase the $\mathrm{Mg}$ electrical activation. This latter can be done by appropriate $\mathrm{p}-\mathrm{GaN}$ layer growth parameters and annealing conditions [30]. However, it is known that at temperatures above $500{ }^{\circ} \mathrm{C}$ in in the presence of hydrogen in the atmosphere, $\mathrm{Mg}-\mathrm{H}$ complexes can form, either passivating the acceptors or compensating them by creation of donor states, leading to a reduced hole concentration [31]. Hence, device manufacturers should also take care that the $\mathrm{Mg}$ active concentration is not decreased during device processing (e.g., annealing for Ohmic contacts).

Another relevant aspect in normally-off HEMT technology with the p-GaN gate is the choice of the metal gate. In fact, the threshold voltage of the device $V_{\text {th }}$ is related, among other things, to the metal/p-GaN Schottky barrier height. Several papers in the last years discussed on the influence of metal gate work-function on the electrical behavior of p-GaN gate HEMTs [29,32-35].

In the early studies, a Pd-based Ohmic gate was adopted on the p-AlGaN cap layer, which allowed to improve the hole injection and the current capability of the device [24]. For that reason, the device was also named "gate injection transistor" (GIT) [24]. However, in that work the fabrication process and the properties of this $\mathrm{Pd} / \mathrm{p}-\mathrm{AlGaN}$ system were not disclosed. 
On the other hand, more recently, TCAD simulations of the metal/p-GaN/AlGaN/GaN system predicted $[32,33]$ that a Schottky metal gate on $\mathrm{p}-\mathrm{GaN}$ should give a higher $\mathrm{V}_{\text {th }}$ and lower leakage with respect to an Ohmic gate. Meneghini et al. [33] showed that a WSiN-based Schottky gate, instead of a standard $\mathrm{Ni} / \mathrm{Au}$ Ohmic contact to $\mathrm{p}-\mathrm{GaN}$, is able to increase the transistor gate voltage swing and reduces the gate leakage current by about four orders of magnitude in the on-state. In general, a high gate leakage in GaN HEMTs translates into a continuous power consumption and heating of the gate driver. Hence, a good Schottky barrier in p-GaN gate HEMTs ensures the absence of large current injection at the gate side, enabling a lower power consumption. For that reason, the use of a Schottky gate on $\mathrm{p}-\mathrm{GaN}$ is today preferred to the Ohmic gate solution.

Table 2 reports some literature data on normally-off p-GaN gate HEMTs. As can be seen, several metals have been used as Schottky gate contact to p-GaN (Mo-, Ni-, Ti-based stacks, etc.). Presently, a good solution is represented by the use of a TiN gate, owing to its thermal and chemical stability and the processing compatibility [30,36-38]. TiN metal gates are typically defined by a stacked-gate self-aligned patterning approach, etching the TiN metal gate and the $\mathrm{p}-\mathrm{GaN}$ in one sequence. Posthuma et al. [30] showed that an optimization of the $\mathrm{Mg}$ activation in the $\mathrm{p}-\mathrm{GaN}$ layer can result in a positive $\mathrm{V}_{\text {th }}$ shift in $\mathrm{p}-\mathrm{GaN}$ HEMTs with a TiN gate, up to $\mathrm{V}_{\text {th }}=2.1 \mathrm{~V}$.

From the data reported in Table 2, a dependence of the threshold voltage $\mathrm{V}_{\text {th }}$ on the metal work function cannot be easily deduced. In fact, the experimental behavior of metal/p-GaN Schottky barriers is typically influenced from surface preparation and/or post-annealing conditions.

In this context, the fabrication flow chart of normally-off HEMT with a p-GaN gate is the most critical part is the definition of the p-GaN gate, as the $\mathrm{p}-\mathrm{GaN}$ layer must be removed selectively from the access regions and left in under the gate. In a "self-aligned" process, the metal gate is deposited first ("gate first") and used at the same time as metal contact for the p-GaN and as hard mask for the dry etch of $\mathrm{p}-\mathrm{GaN}$ in the access regions. While this approach can simplify the fabrication procedure, the high temperature required for the source-drain Ohmic contacts $\left(>800^{\circ} \mathrm{C}\right)[39]$ can promote thermal reactions between metal gate and $\mathrm{p}-\mathrm{GaN}$ degrading the electrical quality of the barrier.

Table 2. Survey of literature data on normally-off HEMTs with p-GaN gates obtained using different Schottky contacts.

\begin{tabular}{|c|c|c|c|}
\hline Metal Gate & $\begin{array}{l}\text { p-GaN Thickness } t \\
\text { and Doping } N_{A}\end{array}$ & $\begin{array}{c}\text { Threshold Voltage } \\
V_{\text {th }}(\mathrm{V})\end{array}$ & Ref. \\
\hline $\mathrm{Mo}_{(100 \mathrm{~nm})} / \mathrm{Ni}{ }_{(20 \mathrm{~nm})}$ & $\mathrm{t}=80 \mathrm{~nm}, \mathrm{~N}_{\mathrm{A}}=3 \times 10^{19} \mathrm{~cm}^{-3}$ & 1.08 & [40] \\
\hline $\mathrm{Mo} / \mathrm{Ti} / \mathrm{Au}$ & $\mathrm{t}=60 \mathrm{~nm}, \mathrm{~N}_{\mathrm{A}} \sim 2 \times 10^{18} \mathrm{~cm}^{-3}$ & 1.9 & [33] \\
\hline $\mathrm{Ni}$ & $\mathrm{t}=100 \mathrm{~nm}, \mathrm{~N}_{\mathrm{A}}=2 \times 10^{19} \mathrm{~cm}^{-3}$ & 1.23 & {$[32,41]$} \\
\hline $\mathrm{Ni} / \mathrm{Au}$ & $\mathrm{t}=60 \mathrm{~nm}, \mathrm{~N}_{\mathrm{A}} \sim 2 \times 10^{18} \mathrm{~cm}^{-3}$ & 1.8 & [33] \\
\hline $\mathrm{Ni}{ }_{(25 \mathrm{~nm})} / \mathrm{Au}{ }_{(120 \mathrm{~nm})}$ & $\mathrm{t}=60 \mathrm{~nm}, \mathrm{~N}_{\mathrm{A}}=1 \times 10^{18} \mathrm{~cm}^{-3}$ & $1.7-2.1$ & [33] \\
\hline $\mathrm{Ni}{ }_{(20 \mathrm{~nm})} / \mathrm{Au}{ }_{(200 \mathrm{~nm})}$ & $\mathrm{t}=50 \mathrm{~nm}, \mathrm{~N}_{\mathrm{A}}=3 \times 10^{18} \mathrm{~cm}^{-3}$ & 0.48 & [42] \\
\hline $\mathrm{Pd}{ }_{(50 \mathrm{~nm})} / \mathrm{Au}{ }_{(150 \mathrm{~nm})}$ & $\mathrm{t}=70 \mathrm{~nm}, \mathrm{~N}_{\mathrm{A}}$ not given & 1.0 & [43] \\
\hline $\mathrm{Ti}(50 \mathrm{~nm}) / \mathrm{Au}(150 \mathrm{~nm})$ & $\mathrm{t}=70 \mathrm{~nm}, \mathrm{~N}_{\mathrm{A}}$ not given & 1.2 & [44] \\
\hline $\mathrm{Ti} / \mathrm{Au}$ & $\mathrm{t}=60 \mathrm{~nm}, \mathrm{~N}_{\mathrm{A}} \sim 2 \times 10^{18} \mathrm{~cm}^{-3}$ & 1.7 & [33] \\
\hline $\mathrm{Ti}_{(30 \mathrm{~nm})} / \mathrm{Al}_{(170 \mathrm{~nm})}$ & $\mathrm{t}=50 \mathrm{~nm}, \mathrm{~N}_{\mathrm{A}}=3 \times 10^{19} \mathrm{~cm}^{-3}$ & 1.5 & [34] \\
\hline TiN & $\mathrm{t}=70 \mathrm{~nm}, \mathrm{~N}_{\mathrm{A}}=1 \times 10^{18} \mathrm{~cm}^{-3}$ & 1.6 & [36] \\
\hline $\mathrm{TiN}$ & $\mathrm{t}=60 \mathrm{~nm}, \mathrm{~N}_{\mathrm{A}}$ not given & 2.1 & {$[30]$} \\
\hline W & $\mathrm{t}=100 \mathrm{~nm}, \mathrm{~N}_{\mathrm{A}}=1 \times 10^{19} \mathrm{~cm}^{-3}$ & 3.0 & {$[32,41]$} \\
\hline WSiN & N.A. & 1.87 & [35] \\
\hline
\end{tabular}

Greco et al. [34] demonstrated that a normally-off operation with $\mathrm{V}_{\text {th }}=1.5 \mathrm{~V}$ can be obtained with a Ti/Al metal gate. However, the structural changes at the $\mathrm{Al} / \mathrm{Ti} / \mathrm{p}-\mathrm{GaN}$ interface upon thermal annealing $\left(400-800^{\circ} \mathrm{C}\right)$ leads to a decrease of the Schottky barrier height, which in turn results into an increase of the leakage current and a negative shift of $V_{\text {th }}$ [34]. This effect is visible in Figure 4, reporting the transfer characteristics of the $\mathrm{p}-\mathrm{GaN}$ HEMTs with a good Al/Ti/p-GaN Schottky gate (non-annealed) and a bad Al/Ti/p-GaN Schottky gate (annealed at $800{ }^{\circ} \mathrm{C}$ ) [34]. 


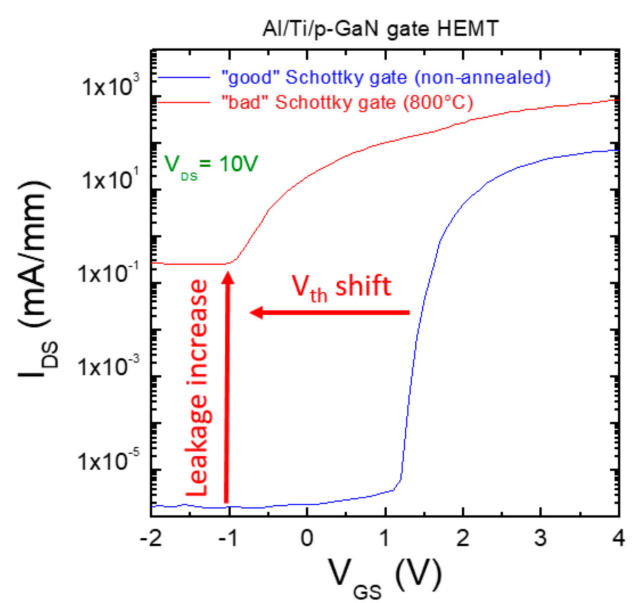

Figure 4. Transfer characteristics ( $\mathrm{I}_{\mathrm{DS}} \mathrm{vs} . \mathrm{V}_{\mathrm{GS}}$ ) at $\mathrm{V}_{\mathrm{DS}}=10 \mathrm{~V}$ of normally-off $\mathrm{p}-\mathrm{GaN}$ gate HEMTs fabricated with a "good" Al/Ti/p-GaN Schottky contact (non-annealed) and with a "bad" Al/Ti/p-GaN Schottky contact (annealed at $800^{\circ} \mathrm{C}$ ).

To avoid the inconvenience related to the leakage of the gate, the $\mathrm{GaN}$ device community is oriented to adopt fabrication processes employing low thermal budgets or stable metallizations to p-GaN compatible with a "gate first" flow. As an example, TiN is often used for these purposes, and employed in commercial devices [23].

Recently, Lükens et al. [40] presented a "self-aligned" process for a normally-off HEMT with p-GaN gate, stable at high temperatures. In particular, they employed a "gate first" process using a Mo-based layer acting simultaneously as gate metallization and p-GaN etch hard mask [40]. Interestingly, the Mo gate was able to sustain the annealing for source-drain Ohmic contacts at $825^{\circ} \mathrm{C}$ without degradation of the barrier.

In this context, it is worth reminding that the great interest towards GaN-based heterostructures grown on large area Si substrates is given by the possibility of power device fabrication inside the existing $\mathrm{Si}$ CMOS lines. Hence, common to all the aforementioned approaches is the need of Au-free metallizations, to guarantee the full compatibility of the p-GaN gate technology with the Si CMOS lines requirements [39].

Today, although the p-GaN gate is the only "real" normally-off HEMT solution that has already reached the commercialization, there are still some reliability issues that are object of intensive investigations. As an example, normally-off p-GaN HEMTs are often affected by gate leakage current, when stressing the gate at forward voltage above 5-6 V. In fact, in forward bias the p-GaN layer acts as a depletion layer for the Schottky contact. The device is equivalent to a back-to-back diode, i.e., a metal/p-GaN Schottky diode in series with a p-GaN/AlGaN/GaN p-n junction [45]. Under high negative bias, the $\mathrm{p}-\mathrm{n}$ diode blocks the gate current, while at high positive gate bias the Schottky gate junction blocks the current. When a high stress voltage is applied to the gate electrode, a large voltage drop and an electric field occur in the depletion region of the $\mathrm{p}-\mathrm{GaN}$ close to the metal interface, thus promoting the formation percolation paths in the $\mathrm{p}-\mathrm{GaN}$ layer that are responsible for the leakage current $[45,46]$. In this sense, the thermal and electrical stability of the metal/p-GaN interface is an important requirement. Moreover, the roughness of the $\mathrm{p}-\mathrm{GaN}$ gate sidewalls (defined by dry etch process) can be also one of the causes of leakage current in these devices [47]. An overview on the reliability issues in normally-off HEMT with $\mathrm{p}-\mathrm{GaN}$ gate is given in reference [35].

For sake of completeness, it must be mentioned that other processes to achieve normally-off HEMTs with p-type GaN-based cap layers have been objects of investigation in the last years.

In some works, the aim was to eliminate in the fabrication flow chart the critical processing step of the selective $\mathrm{p}$-GaN dry etch. As an example, the selective area growth of the $\mathrm{p}$-GaN layer in the gate region can be a promising approach to avoid the need of the selective dry etch of the p-GaN layer in the 
access region [48]. While this technology eliminates the issues related to the plasma-induced damage in the access regions, controlling the electrical properties and the uniformity of the selectively grown $\mathrm{p}$-GaN layer is a challenging aspect. Alternatively, another interesting approach that has been proposed to avoid the plasma etching of the p-GaN layer consists in the "deactivation" of Mg-dopant in the $\mathrm{p}-\mathrm{GaN}$ layer in the access regions by means of a hydrogen plasma treatment $[44,49]$. In fact, hydrogen atoms are able to passivate the $\mathrm{Mg}$-acceptors in the $\mathrm{p}-\mathrm{GaN}$ by the formation of $\mathrm{Mg}-\mathrm{H}$ complexes [31].

On the other hand, Mizutani et al. [50] successfully fabricated normally-off AlGaN/GaN HEMTs using a $\mathrm{p}-\mathrm{In}_{0.23} \mathrm{Ga}_{0.77} \mathrm{~N}$ cap layer, instead of $\mathrm{p}-\mathrm{GaN}$. The basic idea of this approach was to take advantage of the polarization-induced field in the InGaN cap and negative charge in the p-InGaN cap. In fact, in a p-InGaN/AlGaN/GaN structure, the conduction band at the AlGaN/GaN interface is strongly raised, thus leading to normally-off operation. Using this approach, a threshold voltage $\mathrm{V}_{\text {th }}=1.2 \mathrm{~V}$ was obtained [50].

More details on these processes can be found in a recent review paper on normally-off GaN HEMTs with $\mathrm{p}-\mathrm{GaN}$ gate [28].

In spite of the critical processing of the gate region, the normally-off HEMT with a p-GaN gate represents still the only commercially available solution.

\subsection{Recessed Gate Hybrid MISHEMT}

A schematic of the recessed gate hybrid GaN MISHEMT is reported in Figure 5a. In this device, in the gate region the $\mathrm{AlGaN}$ barrier layer is removed by plasma etch and the recessed $\mathrm{GaN}$ region is passivated by an insulator. This device is a hybrid transistor connecting in series the recessed MIS-channel with two access regions having a low resistance (thanks to the presence of the 2DEG). $\mathrm{Zi}$ et al. [51] and Ikeda et al. [52] were among the first who simulated and demonstrated at R\&D level recessed gate hybrid GaN MISHEMTs with threshold voltage $\mathrm{V}_{\text {th }}$ up to $+2 \mathrm{~V}$, specific on-resistance $\mathrm{R}_{\mathrm{ON}}$ $<10 \mathrm{~m} \Omega \mathrm{cm}^{2}$ and breakdown in the $\mathrm{kV}$ range, proposing this solution for power switching applications.

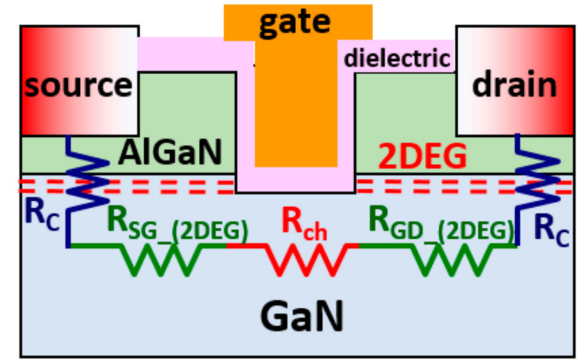

(a)

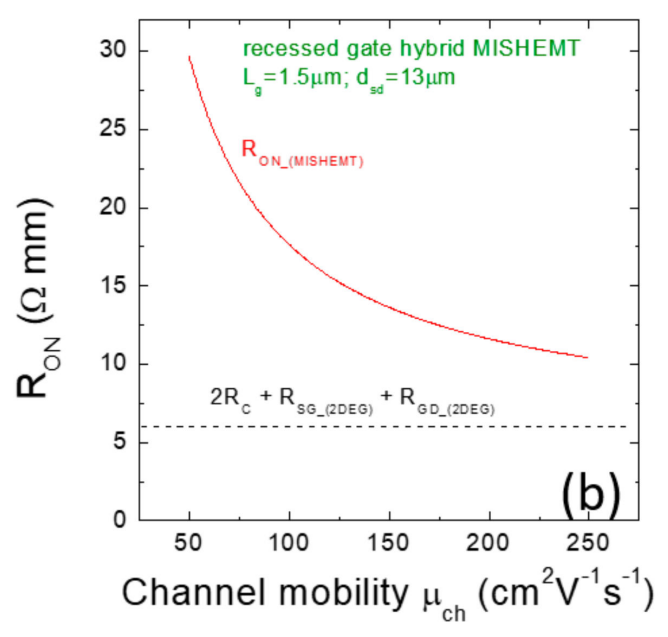

Figure 5. (a) Schematic of a recessed gate hybrid MISHEMT. The contributions to the total series resistance are also indicated. (b) Total resistance of the MISHEMT $R_{O N_{-}(M I S H E M T)}$ as a function of the channel mobility calculated for a device with $\mathrm{L}_{\mathrm{g}}=1.5 \mu \mathrm{m}$ and $\mathrm{d}_{\mathrm{sd}}=13 \mu \mathrm{m}$.

As can be seen in Figure 5a, the total on-resistance of this transistor $R_{O N \_(M I S H E M T)}$ is given by the sum of different contributions:

$$
R O_{N_{-}(M I S H E M T)}=2 R_{C}+R_{S G_{-}(2 D E G)}+R_{G D \_(2 D E G)}+R_{c h}
$$

where $R_{C}$ is the contact resistance of the source/drain electrodes, $R_{S G \_(2 D E G)}$ and $R_{G D \_(2 D E G)}$ are the access resistance contributions and $R_{c h}$ is the resistance of the channel region, i.e., where the 2DEG has 
been removed. The channel resistance $R_{c h}$ is proportional to the gate length $L_{g}$ and decreases with increasing the channel mobility $\mu_{c h}$ [51].

Obviously, the recessed gate region is the most important part of this normally-off transistor. In particular, the surface roughness of the recessed area, the presence of electrically active defects, and the electronic quality of the insulator/GaN interface can have a significant impact on the channel mobility $\mu_{c h}$ and, hence, on the total on-resistance $R_{O N_{-}(M I S H E M T)}$ of the device.

For that reason, the insulator/GaN interfaces in the recessed channel of MISHEMTs are continuously object of investigations.

Figure $5 \mathrm{~b}$ reports the on-resistance $R_{O N_{-}(M I S H E M T)}$ as a function of the channel mobility $\mu_{c h}$ calculated for a recessed gate hybrid GaN MISHEMT, assuming a source-drain distance $d_{\mathrm{sd}}=13 \mu \mathrm{m}$ [53] and a gate length $\mathrm{L}_{\mathrm{g}}=1.5 \mu \mathrm{m}$. In the calculation, realistic values of the contact resistance $\left(R_{C}=0.5 \Omega \mathrm{mm}\right)$ and semiconductor sheet resistance $\left(R_{S H}=400 \Omega / \mathrm{sq}\right)$ were considered. The resistive contribution of recessed channel was assumed considering our experimental measurements on a recessed $\mathrm{SiO}_{2} / \mathrm{GaN}$ MISHEMTs, which gave a channel sheet resistance of $7.3 \mathrm{k} \Omega / \mathrm{sq}$ for a channel mobility value of $110 \mathrm{~cm}^{-2} \cdot \mathrm{V}^{-1} \cdot \mathrm{s}^{-1}[54]$.

As can be seen in Figure $5 b$, for the selected device layout the series resistance decreases of a factor of three with increasing the channel mobility from 50 to $200 \mathrm{~cm}^{2} \cdot \mathrm{V}^{-1} \cdot \mathrm{s}^{-1}$. When the carrier mobility in the recessed channel region is increased, the series resistance $R_{O N_{-}(M I S H E M T)}$ tends to saturate, because the resistive contribution of the recessed channel $R_{c h}$ becomes less important with respect to the other contributions $\left(R_{c}, R_{S G_{-}(2 D E G)}\right.$ and $\left.R_{G D_{-}(2 D E G)}\right)$.

Clearly, in a recessed hybrid MISHEMT controlling the properties of the insulator/GaN interface (i.e., by reducing the roughness, the interface states density, etc.) is mandatory to optimize the channel mobility and, hence, to minimize the device series resistance.

The parameter, which is typically used to describe the electrical behavior of the channel in a recessed gate hybrid MISHEMT, is the so-called "field effect mobility" $\mu_{F E}$, defined as:

$$
\mu_{F E}=\frac{L_{g}}{W C_{o x} V_{D S}}\left(\frac{\partial I_{D S}}{\partial V_{G S}}\right)
$$

where $C_{o x}$ is the gate insulator capacitance per unit area, $L_{g}$ and $W$ are the channel length and width, respectively.

Typically, the curves of the field effect mobility $\mu_{F E}$ as a function of the gate bias $V_{G S}$ increase up to a maximum $\mu_{F E(\max )}$ and then slightly decrease at high $V_{G S}$.

Fiorenza et al. [54] recently analyzed the behavior of the field effect mobility in recessed gate hybrid MISHEMTs employing $\mathrm{SiO}_{2}$ as gate insulator, with respect to several parameters (temperature, surface roughness, electric field, dielectric quality, etc.). In particular, this work highlighted the importance of the reduction of the interface state density in the insulator/GaN system to increase the field effect mobility and reduce the specific on-resistance [54]. As an example, Figure 6 shows the field effect mobility of the recessed gate $\mathrm{SiO}_{2} / \mathrm{GaN}$ MISHEMT measured at $298 \mathrm{~K}$ and $398 \mathrm{~K}$. As can be seen, with increasing the temperature a slight decrease of the maximum peak mobility occurs, which is accompanied by a variation of the slope of the mobility curves at high $\mathrm{V}_{\mathrm{GS}}-\mathrm{V}_{\mathrm{th}}$. This behavior was explained considering different scattering contributions in the total mobility. The results indicated that Coulomb and phonon scattering are the dominant mechanisms limiting the channel mobility of the recessed gate MISHEMT. 


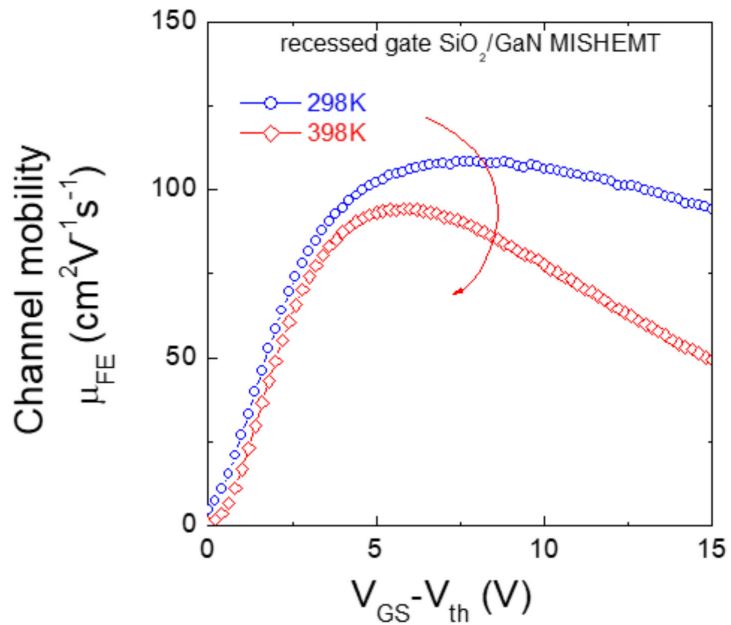

Figure 6. Field effect channel mobility $\mu_{\mathrm{FE}}$ as a function of $\mathrm{V}_{\mathrm{GS}}-\mathrm{V}_{\text {th }}$ of a recessed gate $\mathrm{SiO}_{2} / \mathrm{GaN}$ MISHEMT, measured at room temperature $(298 \mathrm{~K})$ and at $398 \mathrm{~K}$.

Table 3 reports a survey of literature data on relevant parameters for normally-off recessed gate hybrid MISHEMTs employing different gate insulators.

Table 3. Survey of literature data on normally-off recessed gate hybrid GaN MISHEMTs, employing different gate insulators.

\begin{tabular}{|c|c|c|c|c|c|}
\hline Gate Insulator & Insulator Processing & $\begin{array}{c}\mu_{\mathrm{FE}}(\mathrm{Max}) \\
\left(\mathrm{cm}^{2} \cdot \mathrm{V}^{-1} \cdot \mathrm{s}^{-1}\right)\end{array}$ & $\begin{array}{l}V_{\text {th }} \\
(\mathrm{V})\end{array}$ & $\begin{array}{l}\mathrm{R}_{\mathrm{ON}(\mathrm{MISHEMT})} \\
(\Omega \mathrm{mm})\end{array}$ & Ref. \\
\hline $\mathrm{SiO}_{2(60 \mathrm{~nm})}$ & PECVD on SAG of $5 \mathrm{~nm} \mathrm{GaN}$ & 166 & 3.7 & N.A. (FATFET) & [55] \\
\hline $\mathrm{SiO}_{2(60 \mathrm{~nm})}$ & PECVD & 94 & 2.4 & N.A. (FATFET) & [55] \\
\hline $\mathrm{SiO}_{2(50 \mathrm{~nm})}$ & $\begin{array}{l}\text { PECVD }+ \text { Post Annealing at } \\
850{ }^{\circ} \mathrm{C} \text { in } \mathrm{N}_{2}\end{array}$ & 110 & 0.7 & N.A. (FATFET) & [54] \\
\hline $\mathrm{SiN}_{(20 \mathrm{~nm})}$ & PECVD & 120 & 5.2 & $\begin{array}{c}22 \Omega . \mathrm{mm} \\
\text { at } \mathrm{V}_{\mathrm{GS}}=13 \mathrm{~V}\end{array}$ & [56] \\
\hline $\begin{array}{l}\mathrm{SiN}_{(2 \mathrm{~nm}) \mathrm{LT} /} \\
\mathrm{SiN}_{(15 \mathrm{~nm}) \mathrm{HT}}\end{array}$ & $\begin{array}{l}\text { LT-PECVD at } 300^{\circ} \mathrm{C}+ \\
\text { HT-LPCVD at } 780^{\circ} \mathrm{C}\end{array}$ & 160 & 2.37 & $\begin{array}{c}13.2 \Omega . \mathrm{mm} \text { at } \\
\mathrm{V}_{\mathrm{GS}}=15 \mathrm{~V}\end{array}$ & [57] \\
\hline $\mathrm{SiN}_{(17 \mathrm{~nm}) \mathrm{HT}}$ & HT-LPCVD at $780^{\circ} \mathrm{C}$ & 38 & 1.28 & $\begin{array}{l}20 \Omega . \mathrm{mm} \\
\text { at } \mathrm{V}_{\mathrm{GS}}=15 \mathrm{~V}\end{array}$ & [57] \\
\hline $\mathrm{SiN}_{(20 \mathrm{~nm})}$ & $\begin{array}{l}\text { LPCVD on photo-electrochemical } \\
\text { recess }\end{array}$ & 203 & 1.2 & $\begin{array}{c}12.2 \Omega . m m \text { at } \\
\mathrm{V}_{\mathrm{GS}}=17 \mathrm{~V}\end{array}$ & [58] \\
\hline $\mathrm{SiN}_{(15 \mathrm{~nm})}$ & SiN LPCVD at $780^{\circ} \mathrm{C}$ & 49 & 0.8 & $\begin{array}{l}26 \Omega \cdot \mathrm{mm} \text { at } \\
\mathrm{V}_{\mathrm{GS}}=15 \mathrm{~V}\end{array}$ & [59] \\
\hline $\mathrm{GaON}_{/} \mathrm{SiN}_{(15 \mathrm{~nm})}$ & $\mathrm{ICP}$ in $\mathrm{O}_{2}+\mathrm{SiN} \mathrm{LPCVD}$ at $780^{\circ} \mathrm{C}$ & 141 & 1.3 & $\begin{array}{l}12 \Omega \cdot \mathrm{mm} \text { at } \\
\mathrm{V}_{\mathrm{GS}}=15 \mathrm{~V}\end{array}$ & [59] \\
\hline $\mathrm{Al}_{2} \mathrm{O}_{3}(30 \mathrm{~nm})$ & $\begin{array}{l}\text { ALD + Post Annealing at } 800^{\circ} \mathrm{C} \\
\text { in } \mathrm{N}_{2}\end{array}$ & 225 & 2 & $\begin{array}{l}7.8 \Omega . \mathrm{mm} \\
\text { at } \mathrm{V}_{\mathrm{GS}}=6 \mathrm{~V}\end{array}$ & [60] \\
\hline $\mathrm{Al}_{2} \mathrm{O}_{3}(38 \mathrm{~nm})$ & TMAH treated GaN surface & 55 & 3.5 & $\begin{array}{l}27 \Omega . \mathrm{mm} \\
\text { at } \mathrm{V}_{\mathrm{GS}}=15 \mathrm{~V}\end{array}$ & [61] \\
\hline $\mathrm{Al}_{2} \mathrm{O}_{3(10 \mathrm{~nm})}$ & $\begin{array}{c}\text { ALD }+ \text { Post Annealing at } 400^{\circ} \mathrm{C} \\
\text { in } \mathrm{N}_{2}\end{array}$ & 251 & 1.7 & $\begin{array}{c}9.8 \Omega . \mathrm{mm} \text { at } \\
\mathrm{V}_{\mathrm{GS}}=8 \mathrm{~V}\end{array}$ & [62] \\
\hline $\mathrm{Al}_{2} \mathrm{O}_{3(20 \mathrm{~nm})}$ & $\begin{array}{c}\text { ALD + Post Annealing at } 400^{\circ} \mathrm{C} \\
\text { in } \mathrm{N}_{2}\end{array}$ & 148 & 2.9 & $\begin{array}{l}7.2 \Omega . \mathrm{mm} \text { at } \\
\mathrm{V}_{\mathrm{GS}}=9 \mathrm{~V}\end{array}$ & [63] \\
\hline $\mathrm{Al}_{2} \mathrm{O}_{3(30 \mathrm{~nm})}$ & ALD + SAG of access regions & 170 & 3.5 & $\begin{array}{l}9.5 \Omega . \mathrm{mm} \text { at } \\
\mathrm{V}_{\mathrm{GS}}=12 \mathrm{~V}\end{array}$ & [64] \\
\hline $\mathrm{Al}_{2} \mathrm{O}_{3(18 \mathrm{~nm})}$ & $\begin{array}{c}\text { ALD + Post Annealing at } 400^{\circ} \mathrm{C} \\
\text { in } \mathrm{N}_{2}\end{array}$ & 65 & 7.6 & $\begin{array}{c}19.5 \Omega . \mathrm{mm} \text { at } \\
\mathrm{V}_{\mathrm{GS}}=14 \mathrm{~V}\end{array}$ & [65] \\
\hline $\begin{array}{l}\operatorname{AlN}_{(7 \mathrm{~nm})} / \\
\operatorname{SiN}_{(7 \mathrm{~nm})}\end{array}$ & MOCVD & 180 & 1.2 & N.A. (FATFET) & [66] \\
\hline $\begin{array}{l}\mathrm{Al}_{2} \mathrm{O}_{3(5 \mathrm{~nm})} / \\
\mathrm{SiN}_{(25 \mathrm{~nm})}\end{array}$ & SiN LPCVD at $780^{\circ} \mathrm{C}$ & 122 & 1.7 & $\begin{array}{c}12.9 \Omega . \mathrm{mm} \text { at } \\
\mathrm{V}_{\mathrm{GS}}=18 \mathrm{~V}\end{array}$ & [67] \\
\hline
\end{tabular}

In particular, the values of the peak mobility $\mu_{F E(\max )}$ of these devices vary in the range $38-251 \mathrm{~cm}^{2} \cdot \mathrm{V}^{-1} \cdot \mathrm{s}^{-1}$, while the threshold voltage $\mathrm{V}_{\text {th }}$ is usually in the range +1 to $+2 \mathrm{~V}$. For devices 
with a typical gate length of $1.5 \mu \mathrm{m}$, the values of the on-resistance $R_{O N}$ in the operation conditions (i.e., at sufficiently high $\mathrm{V}_{\mathrm{GS}}$ ) are in the range 7.2-26 $\Omega . \mathrm{mm}[57,62-64]$, as can be also seen in the calculation shown in Figure 5b.

Clearly, in recessed gate hybrid MISHEMTs the preparation of the channel surface and post annealing processes are very important. In terms of device manufacturability in Si CMOS lines, a full recess etch of the $\mathrm{AlGaN}$ barrier is preferred, since it is a robust process with a large process window, which limits the $\mathrm{V}_{\text {th }}$ dispersion caused by non-uniform residual AlGaN on the wafer. Moreover, also the deposition process of the dielectric need to be accurately controlled, as it can lead to a degradation of the channel region, especially when this deposition is carried out at high temperatures. The data in Table 3 refer to devices with different geometries and different processes to prepare the recessed channel. Hence, a direct comparison of the electrical parameters of these devices is not straightforward. However, as a general trend, the highest values of the peak mobility $\left(\mu_{F E(\max )}>150 \mathrm{~cm}^{2} \cdot \mathrm{V}^{-1} \cdot \mathrm{s}^{-1}\right)$ correspond to the lowest values of on-resistance $\left(R_{O N}<10 \Omega \cdot \mathrm{mm}\right)$.

As can be seen in Table 3, several dielectric materials have been adopted nowadays for recessed gate normally-off MISHEMTs, the most common being $\mathrm{Al}_{2} \mathrm{O}_{3}, \mathrm{SiO}_{2}$ and $\mathrm{SiN}_{\mathrm{x}}$.

$\mathrm{Al}_{2} \mathrm{O}_{3}$ is typically deposited by Atomic Layer Deposition (ALD) at moderate temperatures $\left(<300{ }^{\circ} \mathrm{C}\right)$. On the other hand, high quality $\mathrm{SiN}_{\mathrm{x}}$ films can be deposited by low-pressure chemical vapor deposition (LPCVD), but high deposition temperatures $\left(800^{\circ} \mathrm{C}\right)$ maybe required to reduce the defect density and improve the film quality.

To overcome this limitation, Cai et al. [59] recently proposed a "channel-engineering" method based on an oxygen-plasma treatment followed by in-situ annealing before $\mathrm{SiN}_{\mathrm{x}}$ gate dielectric deposition on $\mathrm{GaN}$. The formation of a crystalline $\mathrm{GaON}$ nanophase with a high thermal stability and low interface states density was the key factor for the optimization of the performance of $\mathrm{SiN}_{\mathrm{x}} / \mathrm{GaN}$ normally-off MISHEMT, in terms of mobility, threshold voltage and on-resistance [59].

Currently, in spite of many promising results reported on GaN-based recessed gate hybrid MISHEMTs, this technology still suffers from threshold voltage instability issues, related to charge trapping effects inside the gate insulator [66,68-71].

As an example, Figure 7 shows the transfer characteristics ( $I_{D S}$ vs $V_{G S}-V_{t h}$ ) of a recessed gate $\mathrm{SiO}_{2} / \mathrm{GaN}$ MISHEMT acquired under a forward and backward bias sweep. As can been, after the backward bias sweep the transfer characteristics are positively shifted with respect to the forward sweep. The positive threshold voltage shift $\left(\Delta \mathrm{V}_{\text {th }}\right)$ indicates a negative charge trapping in the gate insulator.

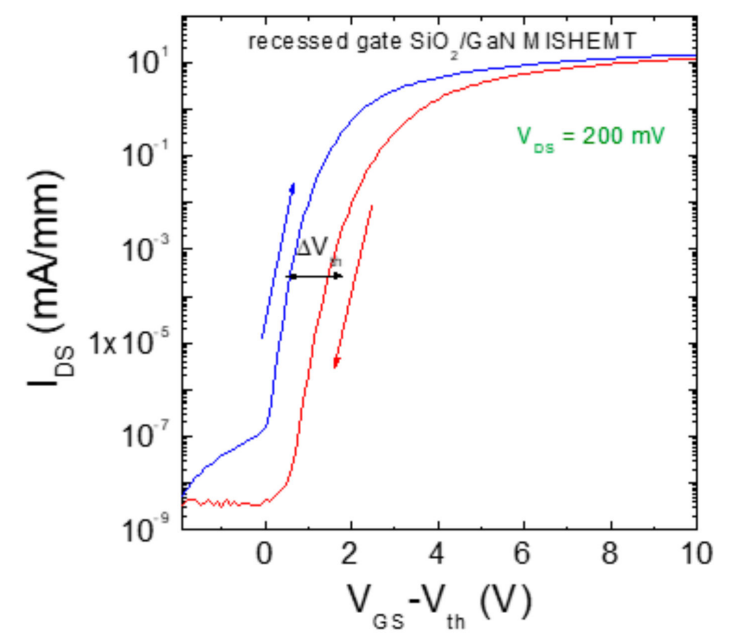

Figure 7. Transfer characteristics $\left(\mathrm{I}_{\mathrm{DS}} \mathrm{vs} \mathrm{V}_{\mathrm{G}}-\mathrm{V}_{\text {th }}\right)$ acquired at $\mathrm{V}_{\mathrm{DS}}=200 \mathrm{mV}$ in a recessed gate MISHEMT under forward and reverse bias sweep, showing a shift of the threshold voltage $\left(\Delta V_{t h}\right)$.

Typically, a threshold voltage instability in MISHEMTs can produce two effects. In the case of a positive $V_{t h}$ shift, like that observed in Figure 7, a degradation of the on-resistance of the device occurs, 
due to the larger bias needed to obtain the same current value. On the other hand, in the case of a negative $V_{\text {th }}$ shift (positive charge trapping), the normally-off behavior can be lost.

Clearly, the occurrence of these charge trapping effects at the gate dielectric represents a big issue for recessed gate MISHEMTs. Hence, this approach has not yet reached an adequate maturity to be commercialized and still remains object of R\&D investigations of the GaN community.

\section{Summary and Outlook}

This paper gave a brief overview on the state-of-the-art of normally-off technology for GaN HEMTs. This topic is very important, as GaN transistors are expected to penetrate significantly the power semiconductor device market in the next years. The presence of the 2DEG in GaN-based heterostructure makes HEMT devices normally-on by nature. Hence, developing reliable solutions for normally-off HEMTs is still a challenge for GaN technology.

As pointed out in the preceding sections, although it is possible to use normally-on HEMTs in power electronics applications by adopting the "cascade" configuration, today the market demands "real" normally-off transistors.

Among the different approaches that have been proposed to achieve normally-off operation in GaN HEMTs, the most important ones are the $\mathrm{p}-\mathrm{GaN}$ gate and the recessed gate hybrid MISHEMT. In this context, it is very important to understand the benefits and drawbacks of these technologies.

A direct comparison of the behavior of normally-off GaN HEMTs with $\mathrm{p}-\mathrm{GaN}$ gate with recessed gate MISHEMTs has been reported by Marcon et al. [72]. In their work, they compared two devices with identical geometries $\left(\mathrm{L}_{\mathrm{g}}=1.5 \mu \mathrm{m}, \mathrm{d}_{\mathrm{sd}}=7.25 \mu \mathrm{m}\right.$ and $\left.\mathrm{W}=100 \mu \mathrm{m}\right)$ fabricated on AlGaN/GaN heterostructures with the same buffer technology.

Figure 8a shows the direct comparison of the transfer characteristics for the two normally-off transistors. As can be seen, while both devices exhibit a similar $\mathrm{V}_{\text {th }}$ of about $1.5 \mathrm{~V}$, a larger output current is carried by the $\mathrm{p}-\mathrm{GaN}$ gate HEMT with respect to the recessed gate MISHEMT. Such a difference is due to the larger series resistance of the recessed gate MISHEMT below the gate region with respect to the p-GaN gate. In fact, as also discussed in Section 3 (Equation (2)), the channel contribution to the on-resistance in a recessed gate MISHEMT linearly scales with the gate length $\mathrm{Lg}_{\mathrm{g}}$ [51]. Hence, in recessed gate hybrid MISHEMTs the gate length is a very important design parameter, and values of $\mathrm{L}_{\mathrm{g}}<1.5 \mu \mathrm{m}$ are typically required to have good performances.
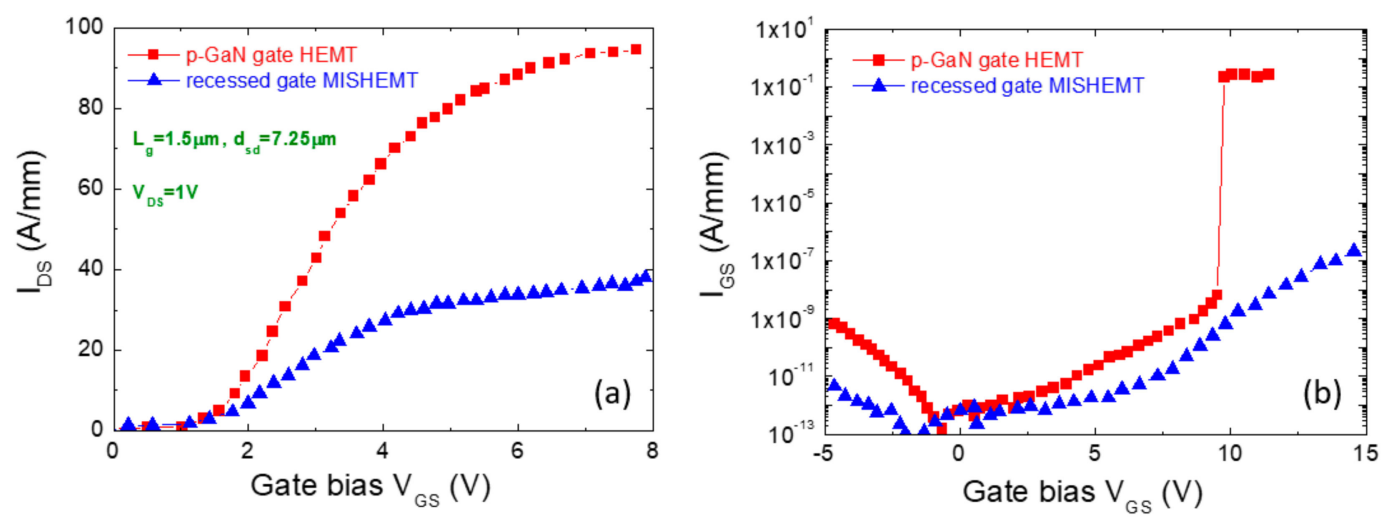

Figure 8. (a) Comparison of the transfer characteristics (at $V_{D S}=1 \mathrm{~V}$ ) of normally-off HEMT with $\mathrm{p}-\mathrm{GaN}$ gate and recessed gate MISHEMT. (b) Forward leakage current of the same devices. The figure has been adapted from reference [72] with the permission of the authors.

On the other hand, the recessed gate MISHEMT exhibits a lower forward leakage current with respect to the $\mathrm{p}-\mathrm{GaN}$ gate, as can be seen in Figure $8 \mathrm{~b}$. This latter is due to the presence of the gate dielectric, which suppresses the leakage current and increases the breakdown $(>9 \mathrm{~V})$. 
Another interesting term of comparison is the hysteresis of the devices. In particular, while this phenomenon is practically absent in $\mathrm{p}-\mathrm{GaN}$ gate HEMTs, it is still a limitation in recessed gate hybrid MISHEMTs, due to the presence of interface states and bulk trap in the gate dielectric. Hence, further work on the gate dielectric is required to optimize the technology of normally-off recessed gate MISHEMTs.

The advantages and disadvantages, in terms of processing and performances, of the three main normally-off GaN HEMT designs described in the previous sections are summarized in Table 4.

Table 4. Advantages and disadvantages of the three main normally-off GaN HEMT solutions in terms of processing and performances: "cascode" configuration, p-GaN gate and recessed gate hybrid MISHEMT.

\begin{tabular}{|c|c|c|}
\hline Normally-Off Design & Advantages & Disadvantages \\
\hline Cascode & $\begin{array}{c}\text {-Use of standard MOSFET gate } \\
\text { driver } \\
\text {-Stable } \mathrm{V}_{\mathrm{th}}>0 \text { of the Si MOSFET }\end{array}$ & $\begin{array}{c}\text {-Package complexity } \\
\text {-Optimization of Si MOSFFET needed in } \\
\text { each application } \\
\text {-Not suitable for low voltage }(<600 \mathrm{~V}) \text { and } \\
\text { high frequency }(>1 \mathrm{MHz}) \text { applications }\end{array}$ \\
\hline p-GaN gate & $\begin{array}{l}\text {-Low resistance under the gate } \\
\text {-No dielectric issues }\end{array}$ & $\begin{array}{l}\text {-Optimization of p-GaN etching needed for } \\
\text { low access resistance and better reliability } \\
\text {-Limited positive gate voltage swing }\end{array}$ \\
\hline $\begin{array}{l}\text { Recessed gate hybrid } \\
\text { MISHEMT }\end{array}$ & $\begin{array}{l}\text {-Large forward breakdown } \\
\text {-Standard device driving in } \\
\text { applications }\end{array}$ & $\begin{array}{l}\text { - Not suitable for low voltage application } \\
(100 \mathrm{~V}) \text {, due to the gate channel resistance } \\
\text {-Critical impact of the gate module } \\
\text { (interface and dielectric) on device } \\
\text { performances ( } \mathrm{R}_{\mathrm{ON}} \text { and reliability) }\end{array}$ \\
\hline
\end{tabular}

In conclusion, today, the $\mathrm{p}-\mathrm{GaN}$ gate approach remains the only one that is commercially available. However, significant R\&D progress has been achieved also in the recessed gate MISHEMT technology and continuous efforts are devoted to improve further this technology.

Clearly, both approaches still present several open issues that must be addressed to optimize the reliability and manufacturability. Moreover, each solution exhibits advantages and disadvantages, in terms of processing and performances in different applications. Hence, it can be expected that the choice of the normally-off design will depend on the targeted application. In this context, the p-GaN gate will be probably more suitable for the low- and medium-voltage applications, while the MISHEMT technology will be used for applications at higher voltages. Moreover, the market penetration of normally-off GaN-based solutions in power electronics will be related also to the decrease of the materials cost and to the improvement of the material quality, which in turn is affects the device reliability. In this scenario, from an academic point of view, great efforts of the research community will be required in the next years to reach a more complete understanding of the physics of GaN-based materials and devices.

Author Contributions: Supervision and writing—review and editing, F.R.; experiments, G.G., P.F. and F.I.; data analysis and discussion, F.R., G.G. and P.F.

Funding: This work was partially funded by the Italian Ministry for Education, University and Research (MIUR) in the framework of the National Project PON EleGaNTe (Electronics on GaN-based Technologies), ARS01_01007.

Acknowledgments: The authors would like to thank the colleagues at CNR-IMM and STMicroelectronics for their technical assistance and scientific contributions. Among them, F. Giannazzo and R. Lo Nigro (CNR-IMM) are acknowledged for the fruitful scientific discussions, S. Di Franco and C. Bongiorno (CNR-IMM) for clean room operation and TEM analyses, and S. Reina and A. Parisi (STMicroelectronics) for their support in the electrical characterization. Moreover, F.R. would like to thank the organizers of Symposium X ("Silicon carbide and related materials for energy saving applications") of the EMRS Spring Meeting 2019 for the invitation to contribute to this event with an invited paper on this topic.

Conflicts of Interest: The authors declare no conflict of interest. 


\section{References}

1. International Energy Agency (IEA). World Energy Outlook Report for 2016 (WEO-2016); IEA: Paris, France, 2016.

2. Ren, F.; Zolper, J.C. Wide Band Gap Electronic Devices; World Scientific: Singapore, 2003.

3. Kimoto, T.; Cooper, J.A. Fundamentals of Silicon Carbide Technology: Growth, Characterization, Devices and Applications; John Wiley \& Sons Singapore Pte. Ltd.: Singapore, 2014.

4. Roccaforte, F.; Fiorenza, P.; Greco, G.; Lo Nigro, R.; Giannazzo, F.; Patti, A.; Saggio, M. Challenges for energy efficient wide band gap semiconductor power devices. Phys. Status Solidi A 2014, 211, 2063-2071. [CrossRef]

5. Ambacher, O.; Smart, J.; Shealy, J.R.; Weimann, N.G.; Chu, K.; Murphy, M.; Schaff, W.J.; Eastman, L.F.; Dimitrov, R.; Wittmer, L.; et al. Two-dimensional electron gases induced by spontaneous and piezoelectric polarization charges in N- and Ga-face AlGaN/GaN heterostructures. J. Appl. Phys. 1999, 85, 3222-3233. [CrossRef]

6. Baliga, B.J. Power Semiconductor Device Figure of Merit for High-Frequency Applications. IEEE Electron Device Lett. 1989, 10, 455-457. [CrossRef]

7. Roccaforte, F.; Giannazzo, F.; Iucolano, F.; Eriksson, J.; Weng, M.H.; Raineri, V. Surface and interface issues in wide band gap semiconductor electronics. Appl. Surf. Sci. 2010, 256, 5727-5735. [CrossRef]

8. Shur, M.; Rumyanstev, S.; Levinshtein, M. SiC Materials and Devices; World Scientific: Singapore, 2006.

9. Asif Khan, M.; Kuznia, J.N.; Bhattarai, A.R.; Olson, D.T. Metal semiconductor field effect transistor based on single crystal GaN. Appl. Phys. Lett. 1993, 62, 1786-1787. [CrossRef]

10. Roccaforte, F.; Fiorenza, P.; Lo Nigro, R.; Giannazzo, F.; Greco, G. Physics and technology of gallium nitride materials for power electronics. Riv. Nuovo Cim. 2018, 41, 625-681.

11. Villamor, A.; Zong, Z. Power GaN 2017: Epitaxy, Devices, Applications and Technology Trends 2017 Report; Yole Développement: Lyon, France, 2017.

12. Chen, K.J.; Zhou, C. Enhancement-mode AlGaN/GaN HEMT and MIS-HEMT technology. Phys. Status Solidi A 2011, 208, 434-438. [CrossRef]

13. Su, M.; Chen, C.; Rajan, S. Prospects for the application of GaN power devices in hybrid electric vehicle drive systems. Semicond. Sci. Technol. 2013, 28, 074012. [CrossRef]

14. Scott, M.J.; Fu, L.; Zhang, X.; Li, J.; Yao, C.; Sievers, M.; Wang, J. Merits of gallium nitride based power conversion. Semicond. Sci. Technol. 2013, 28, 074013. [CrossRef]

15. Saito, W.; Takada, Y.; Kuraguchi, M.; Tsuda, K.; Omura, I. Recessed-gate structure approach toward normally off high-Voltage AlGaN/GaN HEMT for power electronics applications. IEEE Electron Device Lett. 2006, 53, 356-362. [CrossRef]

16. Kumar, V.; Kuliev, A.; Tanaka, T.; Otoki, Y.; Adesida, I. High transconductance enhancement-mode AlGaN/GaN HEMTs on SiC substrate. Electron. Lett. 2003, 39, 1758-1760. [CrossRef]

17. Cai, Y.; Zhou, Y.; Lau, K.M.; Chen, K.J. Control of Threshold Voltage of AlGaN/GaN HEMTs by Fluoride-Based Plasma Treatment: From Depletion Mode to Enhancement Mode. IEEE Electron Device Lett. 2006, 53, 2207-2215. [CrossRef]

18. Greco, G.; Giannazzo, F.; Frazzetto, A.; Raineri, V.; Roccaforte, F. Near-surface processing on AlGaN/GaN heterostructures: A nanoscale electrical and structural characterization. Nanoscale Res. Lett. 2011, 6, 132. [CrossRef] [PubMed]

19. Zhang, Y.; Sun, M.; Joglekar, S.J.; Fujishima, T.; Palacios, T. Threshold voltage control by gate oxide thickness in fluorinated $\mathrm{GaN}$ metal-oxide semiconductor high-electron-mobility transistors. Appl. Phys. Lett. 2013, 103, 033524. [CrossRef]

20. Lorenz, A.; Derluyn, J.; Das, J.; Cheng, K.; Degroote, S.; Medjdoub, F.; Germain, M.; Borghs, G. Influence of thermal anneal steps on the current collapse of fluorine treated enhancement mode SiN/AlGaN/GaN HEMTs. Phys. Status Solidi C 2009, 6, S996-S998. [CrossRef]

21. Baliga, B.J. Silicon Carbide Power Devices; World Scientific Publising Co Pte. Ltd.: Singapore, 2005.

22. Jones, E.A.; Wang, F.F.; Costinett, D. Review of commercial GaN power devices and GaN-based converter design challenges. IEEE J. Emerg. Sel. Top. Power Electron. 2016, 4, 707-719. [CrossRef]

23. Lidow, A.; Strydom, J.; de Rooij, M.; Reutsch, D. GaN Transistors for Efficient Power Conversion; John Wiley \& Sons Ltd.: Chichester, UK, 2015. 
24. Uemoto, Y.; Hikita, M.; Ueno, H.; Matsuo, H.; Ishida, H.; Yanagihara, M.; Ueda, T.; Tanaka, T.; Ueda, D. Gate Injection Transistor (GIT) - A Normally-Off AlGaN/GaN Power Transistor Using Conductivity Modulation. IEEE Trans. Electron Devices 2007, 54, 3393-3399. [CrossRef]

25. Fujii, T.; Tsuyukuchi, N.; Hirose, Y.; Ywaya, M.; Kamiyama, S.; Amano, H.; Akasaki, I. Fabrication of enhancement-mode $\mathrm{Al}_{\mathrm{x}} \mathrm{Ga}_{1-\mathrm{x}} \mathrm{N} / \mathrm{GaN}$ junction heterostructure field-effect transistors with p-type GaN gate contact. Phys. Status Solidi C 2007, 4, 2708-2711. [CrossRef]

26. Hilt, O.; Knauer, A.; Brunner, F.; Bahat-Treidel, E.; Würfl, J. Normally-off AlGaN/GaN HFET with p-type GaN Gate and AlGaN Buffer. In Proceedings of the 22nd International Symposium on Power Semiconductor Devices and IC's (ISPSD2010), Hiroshima, Japan, 6-10 June 2010; pp. 347-350.

27. Hilt, O.; Brunner, F.; Cho, E.; Knauer, A.; Bahat-Treidel, E.; Würfl, J. Normally-off High-Voltage p-GaN Gate GaN HFET with Carbon-Doped Buffer. In Proceedings of the 23rd International Symposium on Power Semiconductor Devices and IC's (ISPSD2011), San Diego, CA, USA, 23-26 May 2011; pp. 239-242. [CrossRef]

28. Greco, G.; Iucolano, F.; Roccaforte, F. Review of technology for normally-off HEMTs with p-GaN gate. Mater. Sci. Semicond. Proc. 2018, 78, 96-106. [CrossRef]

29. Efthymiou, L.; Longobardi, G.; Camuso, G.; Chien, T.; Chen, M.; Udrea, F. On the physical operation and optimization of the p-GaN gate in normally-off GaN HEMT devices. Appl. Phys. Lett. 2017, 110, 123502. [CrossRef]

30. Posthuma, N.E.; You, S.; Liang, H.; Ronchi, N.; Kang, X.; Wellekens, D.; Saripalli, Y.N.; Decoutere, S. Impact of Mg out-diffusion and activation on the $\mathrm{p}-\mathrm{GaN}$ gate HEMT device performance. In Proceedings of the 28th International Symposium on Power Semiconductor Devices and ICs (ISPSD2016), Prague, Czech Republic, 12-16 June 2016; pp. 95-98. [CrossRef]

31. Götz, W.; Johnson, N.M.; Walker, J.; Bour, D.P.; Amano, H.; Akasaki, I. Hydrogen passivation of Mg acceptors in GaN grown by metalorganic chemical vapor deposition. Appl. Phys. Lett. 1995, 67, 2666-2668. [CrossRef]

32. Hwang, I.; Kim, J.; Choi, H.S.; Choi, H.; Lee, J.; Kim, K.Y.; Park, J.-B.; Lee, J.C.; Ha, J.; Oh, J.; et al. p-GaN Gate HEMTs with Tungsten Gate Metal for High Threshold Voltage and Low Gate Current. IEEE Electron Device Lett. 2013, 34, 202-204. [CrossRef]

33. Lee, F.; Su, L.-Y.; Wang, C.-H.; Wu, Y.-R.; Huang, J. Impact of Gate Metal on the Performance of p-GaN/AlGaN/GaN High Electron Mobility Transistors. IEEE Electron Device Lett. 2015, 36, 232-234. [CrossRef]

34. Greco, G.; Iucolano, F.; Di Franco, S.; Bongiorno, C.; Patti, A.; Roccaforte, F. Effects of Annealing Treatments on the Properties of Al/Ti/p-GaN Interfaces for Normally OFF p-GaN HEMTs. IEEE Trans. Electron Devices 2016, 63, 2735-2741. [CrossRef]

35. Meneghini, M.; Hilt, O.; Würfl, J.; Meneghesso, G. Technology and reliability of Normally-Off GaN HEMTs with p-type gate. Energies 2017, 10, 153. [CrossRef]

36. Wu, T.-L.; Marcon, D.; You, S.; Posthuma, N.; Bakeroot, B.; Stoffel, S.; Van Hove, M.; Groeseneken, G.; Decoutere, S. Forward Bias Gate Breakdown Mechanism in Enhancement-Mode p-GaN Gate AlGaN/GaN High-Electron Mobility Transistors. IEEE Electron Device Lett. 2015, 36, 1001-1003. [CrossRef]

37. Greco, G.; Iucolano, F.; Giannazzo, F.; Di Franco, S.; Corso, D.; Smecca, E.; Alberti, A.; Patti, A.; Roccaforte, F. Metal/P-GaN Contacts on AlGaN/GaN Heterostructures for Normally-Off HEMTs. Mater. Sci. Forum 2016, 858, 1170-1173. [CrossRef]

38. Sayadi, L.; Iannaccone, G.; Sicre, S.; Häberlen, O.; Curatola, G. Threshold Voltage Instability in p-GaN Gate AlGaN/GaN HFETs. IEEE Trans. Electron Devices 2019, 65, 2454-2460. [CrossRef]

39. Greco, G.; Iucolano, F.; Roccaforte, F. Ohmic contacts to Gallium Nitride materials. Appl. Surf. Sci. 2016, 383, 324-345. [CrossRef]

40. Lükens, G.; Hanhn, H.; Kalisch, H.; Vescan, A. Self-Aligned Process for Selectively Etched p-GaN-Gated AlGaN/GaN-on-Si HFETs. IEEE Trans. Electron Devices 2018, 65, 3732-3738. [CrossRef]

41. Hwang, I.; Oh, J.; Soon Choi, H.; Kim, J.; Choi, H.; Kim, J.; Chong, S.; Shin, J.; Chung, U.-I. Source-Connected p-GaN Gate HEMTs for Increased Threshold Voltage. IEEE Electron Device Lett. 2013, 34, 605-607. [CrossRef]

42. Chiu, H.-C.; Chang, Y.-S.; Li, B.-H.; Wang, H.-C.; Kao, H.-L.; Hu, C.-W.; Xuan, R. High-performance Normally Off $\mathrm{p}-\mathrm{GaN}$ Gate HEMT with composite $\mathrm{AlN} / \mathrm{Al}_{0.17} \mathrm{Ga}_{0.83} \mathrm{~N} / \mathrm{Al}_{0.3} \mathrm{Ga}_{0.7} \mathrm{~N}$ barrier layers design. J. Electron Dev. Soc. 2018, 6, 201-206. [CrossRef] 
43. Chang, T.-F.; Hsiao, T.-C.; Huang, C.-F.; Kuo, W.-H.; Ling, S.-F.; Samudra, G.-S.; Liang, Y.C. Phenomenon of Drain Current Instability onp-GaN Gate AlGaN/GaN HEMTs. IEEE Trans. Electron Devices 2015, 62, 339-345. [CrossRef]

44. Xu, N.; Hao, R.; Chen, F.; Zhang, X.; Zhang, H.; Zhang, P.; Ding, X.; Song, L.; Yu, G.; Cheng, K.; et al. Gate leakage mechanisms in normally off $\mathrm{p}-\mathrm{GaN} / \mathrm{AlGaN} / \mathrm{GaN}$ high electron mobility transistors. Appl. Phys. Lett. 2018, 113, 152104. [CrossRef]

45. Tallarico, A.N.; Stoffel, S.; Magnone, P.; Posthuma, N.; Sangiorgi, E.; Decoutere, S.; Fiegna, C. PBTI in GaN-HEMTs With p-Type Gate: Role of the Aluminum Content on $\Delta \mathrm{V}_{\mathrm{TH}}$ and Underlying Degradation Mechanisms. IEEE Electron Device Lett. 2017, 38, 99-102. [CrossRef]

46. Ťapajna, M.; Hilt, O.; Bahat-Treidel, E.; Würfl, J.; Kuzmík, J. Gate Reliability Investigation in Normally-Off p-Type-GaN Cap/AlGaN/GaN HEMTs Under Forward Bias Stress. IEEE Electron Device Lett. 2016, 37, 385-388. [CrossRef]

47. Stockman, A.; Canato, E.; Tajalli, A.; Meneghini, M.; Meneghesso, G.; Zanoni, E.; Moens, P.; Bakeroot, B. On the origin of the leakage current in p-Gate AlGaN/GaN HEMTs. In Proceedings of the 2018 IEEE International Reliability Physics Symposium (IRPS2018), Burlingame, CA, USA, 11-15 March 2018; pp. 4B.5-1-4B.5-4. [CrossRef]

48. Yuliang, H.; Lian, Z.; Zhe, C.; Yun, Z.; Yujie, A.; Yongbing, Z.; Hongxi, L.; Junxi, W.; Jinmin, L. AlGaN/GaN high electron mobility transistors with selective area grown p-GaN gates. J. Semicond. 2016, 37, 114002.

49. Hao, R.; Fu, K.; Yu, G.; Li, W.; Yuan, J.; Song, L.; Zhang, Z.; Sun, S.; Li, X.; Cai, Y.; et al. Normally-off p-GaN/AlGaN/GaN high electron mobility transistors using hydrogen plasma treatment. Appl. Phys. Lett. 2016, 109, 152106.

50. Mizutani, T.; Yamada, H.; Kishimoto, S.; Nakamura, F. Normally off AlGaN/GaN high electron mobility transistors with p-InGaNcap layer. J. Appl. Phys. 2013, 113, 034502. [CrossRef]

51. Li, Z.; Chow, T.P. Channel scaling of hybrid GaN MOS-HEMTs. Solid State Electron. 2011, 56, 111-115. [CrossRef]

52. Ikeda, N.; Tamura, R.; Kokawa, T.; Kambayashi, H.; Sato, Y.; Nomura, T.; Kato, S. Over 1.7 kV normally-off GaN hybrid MOS-HFETs with a lower on-resistance on a Si substrate. In Proceedings of the 23rd International Symposium on Power Semiconductor Devices and IC's (ISPSD2011), San Diego, CA, USA, 23-26 May 2011; pp. 284-287. [CrossRef]

53. Ikeda, N.; Li, J.; Kato, K.; Kaya, S.; Kazama, T.; Kokawa, T.; Sato, Y.; Iwami, M.; Nomura, T.; Masuda, M.; et al. High-Power GaN HFETs on Si Substrate. Furukawa Rev. 2008, 34, 17-23.

54. Fiorenza, P.; Greco, G.; Iucolano, F.; Patti, A.; Roccaforte, F. Channel Mobility in GaN Hybrid MOS-HEMT Using $\mathrm{SiO}_{2}$ as Gate Insulator. IEEE Trans. Electron Devices 2017, 64, 2893-2899. [CrossRef]

55. Kambayashi, H.; Satoh, Y.; Kokawa, T.; Ikeda, N.; Nomura, T.; Kato, S. High field-effect mobility normally-off AlGaN/GaN hybrid MOS-HFETon Si substrate by selective area growth technique. Solid State Electron. 2011, 56, 163-167. [CrossRef]

56. Oka, T.; Nozawa, T. AlGaN/GaN recessed MIS-Gate HFET with high-threshold-voltage Normally-Off operation for power electronics applications. IEEE Electron Device Lett. 2008, 29, 668-670. [CrossRef]

57. Hua, M.; Zhang, Z.; Wei, J.; Lei, J.; Tang, G.; Fu, K.; Cai, Y.; Zhang, B.; Chen, K.J. Integration of LPCVD-SiN Gate Dielectric with Recessed-gate E-mode GaN MIS-FETs: Toward High Performance, High Stability and Long TDDB Lifetime. In Proceedings of the International Electron Device Meeting 2016 (IEDM 2016), San Francisco, CA, USA, 3-7 December 2016; pp. 260-263. [CrossRef]

58. Zhang, Z.; Qin, S.; Fu, K.; Yu, G.; Li, W.; Zhang, X.; Sun, S.; Song, L.; Li, S.; Hao, R.; et al. Fabrication of normally-off AlGaN/GaN metal-insulator-semiconductor high-electronmobility transistors by photo-electrochemical gate recess etching in ionic liquid. Appl. Phys. Express 2016, 9, 084102. [CrossRef]

59. Cai, X.; Hua, M.; Zhang, Z.; Yang, S.; Zheng, Z.; Cai, Y.; Chen, K.J.; Wang, N. Atomic-scale identification of crystalline GaON nanophase for enhanced GaN MIS-FET channel. Appl. Phys. Lett. 2019, 114, 053109. [CrossRef]

60. Im, K.-S.; Ha, J.-B.; Kim, K.-W.; Lee, J.-S.; Kim, D.-S.; Hahm, S.-H.; Lee, J.-H. Normally Off GaN MOSFET based on AlGaN/GaN heterostructure with extremely high 2DEG density grown on Silicon substrate. IEEE Electron Device Lett. 2010, 31, 192-194. 
61. Kim, K.-W.; Jung, S.-D.; Kim, D.-S.; Kang, H.-S.; Im, K.-S.; Oh, J.-J.; Ha, J.-B.; Shin, J.-K.; Lee, J.H. Effects of TMAH Treatment on Device Performance of Normally Off $\mathrm{Al}_{2} \mathrm{O}_{3} / \mathrm{GaN}$ MOSFET. IEEE Electron Device Lett. 2011, 32, 1376-1378. [CrossRef]

62. Wang, Y.; Wang, M.; Xie, B.; Wen, C.P.; Wang, J.; Hao, Y.; Wu, W.; Chen, K.J.; Shen, B. High-Performance Normally-Off $\mathrm{Al}_{2} \mathrm{O}_{3} / \mathrm{GaN}$ MOSFET Using a Wet Etching-Based Gate Recess Technique. IEEE Electron Device Lett. 2013, 34, 1370-1372. [CrossRef]

63. Wang, M.; Wang, Y.; Zhang, C.; Xie, B.; Wen, C.P.; Wang, J.; Hao, Y.; Wu, W.; Chen, K.J.; Shen, B. 900 V/1.6 $\mathrm{m} \Omega \mathrm{cm}^{2}$ Normally Off $\mathrm{Al}_{2} \mathrm{O}_{3} / \mathrm{GaN}$ MOSFET on Silicon Substrate. IEEE Trans. Electron Devices 2014, 61, 2035-2040. [CrossRef]

64. Yao, Y.; He, Z.; Yang, F.; Shen, Z.; Zhang, J.; Ni, Y.; Li, J.; Wang, S.; Zhou, G.; Zhong, J.; et al. Normally-off GaN recessed-gate MOSFET fabricated by selective area growth technique. Appl. Phys. Express 2014, 7, 016502. [CrossRef]

65. Zhou, Q.; Liu, L.; Zhang, A.; Chen, B.; Jin, Y.; Shi, Y.; Wang, Z.; Chen, W.; Zhang, B. 7.6 V Threshold Voltage High-Performance Normally-Off $\mathrm{Al}_{2} \mathrm{O}_{3} / \mathrm{GaN}$ MOSFET Achieved by Interface Charge Engineering. IEEE Electron Device Lett. 2016, 37, 165-168. [CrossRef]

66. Greco, G.; Fiorenza, P.; Iucolano, F.; Severino, A.; Giannazzo, F.; Roccaforte, F. Conduction Mechanisms at Interface of AlN/SiN Dielectric Stacks with AlGaN/GaN Heterostructures for Normally-off High Electron Mobility Transistors: Correlating Device Behavior with Nanoscale Interfaces Properties. Acs Appl. Mater. Interfaces 2017, 9, 35383-35390. [CrossRef] [PubMed]

67. Wang, H.; Wang, J.; Liu, J.; Li, M.; He, Y.; Wang, M.; Yu, M.; Wu, W.; Zhou, Y.; Dai, G. Normally-off fully recess-gated GaN metal-insulator-semiconductor field-effect transistor using $\mathrm{Al}_{2} \mathrm{O}_{3} / \mathrm{Si}_{3} \mathrm{~N}_{4}$ bilayer as gate dielectrics. Appl. Phys. Express 2017, 10, 106502. [CrossRef]

68. Fiorenza, P.; Greco, G.; Giannazzo, F.; Iucolano, F.; Roccaforte, F. Effects of interface states and near interface traps on the threshold voltage stability of $\mathrm{GaN}$ and $\mathrm{SiC}$ transistors employing $\mathrm{SiO}_{2}$ as gate dielectric. J. Vac. Sci. Technol. B 2017, 35, 01A101. [CrossRef]

69. Acurio, E.; Crupi, F.; Magnone, P.; Trojman, L.; Iucolano, F. Impact of AlN layer sandwiched between the $\mathrm{GaN}$ and the $\mathrm{Al}_{2} \mathrm{O}_{3}$ layers on the performance and reliability of recessed AlGaN/GaN MOS-HEMTs. Microelectron. Eng. 2017, 178, 42-47. [CrossRef]

70. Acurio, E.; Crupi, F.; Magnone, P.; Trojman, L.; Meneghesso, G.; Iucolano, F. On recoverable behavior of PBTI in AlGaN/GaN MOS-HEMT. Solid State Electron. 2017, 132, 49-56. [CrossRef]

71. Fiorenza, P.; Greco, G.; Schilirò, E.; Iucolano, F.; Lo Nigro, R.; Roccaforte, F. Determining oxide trapped charges in $\mathrm{Al}_{2} \mathrm{O}_{3}$ insulating films on recessed $\mathrm{AlGaN} / \mathrm{GaN}$ heterostructures by gate capacitance transients measurements. Jpn. J. Appl. Phys. 2018, 57, 050307. [CrossRef]

72. Marcon, D.; Van Hove, M.; De Jaeger, B.; Posthuma, N.; Wellekens, D.; You, S.; Kang, X.; Wu, T.-L.; Willems, M.; Stoffel, S.; et al. Direct comparison of GaN-based e-mode architectures (recessed MISHEMT and p-GaN HEMTs) processed on 200 mm GaN-on-Si with Au-free technology. Proc. Spie 2015, 9363, 936311. [CrossRef] 